\title{
A Comparison of Central Composite Design and Taguchi Method for Optimizing Fenton Process
}

\author{
Anam Asghar, Abdul Aziz Abdul Raman, and Wan Mohd Ashri Wan Daud \\ Chemical Engineering Department, Faculty of Engineering, University of Malaya, 50603 Kuala Lumpur, Malaysia \\ Correspondence should be addressed to Abdul Aziz Abdul Raman; azizraman@um.edu.my
}

Received 21 April 2014; Revised 22 July 2014; Accepted 6 August 2014; Published 27 August 2014

Academic Editor: Seval Kutlu Akal Solmaz

Copyright (C) 2014 Anam Asghar et al. This is an open access article distributed under the Creative Commons Attribution License, which permits unrestricted use, distribution, and reproduction in any medium, provided the original work is properly cited.

\begin{abstract}
In the present study, a comparison of central composite design (CCD) and Taguchi method was established for Fenton oxidation. [Dye $]_{\text {ini }}$, Dye : Fe $e^{+2}, \mathrm{H}_{2} \mathrm{O}_{2}: \mathrm{Fe}^{+2}$, and $\mathrm{pH}$ were identified control variables while COD and decolorization efficiency were selected responses. $L_{9}$ orthogonal array and face-centered CCD were used for the experimental design. Maximum $99 \%$ decolorization and $80 \%$ COD removal efficiency were obtained under optimum conditions. $R$ squared values of 0.97 and 0.95 for CCD and Taguchi method, respectively, indicate that both models are statistically significant and are in well agreement with each other. Furthermore, Prob $>F$ less than 0.0500 and ANOVA results indicate the good fitting of selected model with experimental results. Nevertheless, possibility of ranking of input variables in terms of percent contribution to the response value has made Taguchi method a suitable approach for scrutinizing the operating parameters. For present case, $\mathrm{pH}$ with percent contribution of $87.62 \%$ and $66.2 \%$ was ranked as the most contributing and significant factor. This finding of Taguchi method was also verified by 3D contour plots of CCD. Therefore, from this comparative study, it is concluded that Taguchi method with 9 experimental runs and simple interaction plots is a suitable alternative to CCD for several chemical engineering applications.
\end{abstract}

\section{Introduction}

Fenton oxidation is an efficient and widely applied AOPs, which utilizes ferrous iron $\left(\mathrm{Fe}^{+2}\right)$ and hydrogen peroxide $\left(\mathrm{H}_{2} \mathrm{O}_{2}\right)$ under acidic conditions to produce hydroxyl radical $\left(\mathrm{HO}^{\circ}\right)$ (reaction 1). Formation of $\mathrm{HO}^{\circ}$ is advantageous because it is highly oxidative $(E=2.8 \mathrm{eV})$ and nonselective in nature $[1,2]$. However, the performance of Fenton reaction is influenced by several parameters such as $\mathrm{pH}$, reaction time, initial concentrations of Dye, $\mathrm{H}_{2} \mathrm{O}_{2}$, and $\mathrm{Fe}^{+2}$ catalysts $[3,4]$. Moreover, excess consumption of chemicals $\left(\mathrm{Fe}^{+2}\right.$ salt, $\mathrm{H}_{2} \mathrm{O}_{2}$ acid/base) and high cost of $\mathrm{H}_{2} \mathrm{O}_{2}$ have made this process economically nonviable $[5,6]$. Therefore, a systematic way of planning, execution, and statistical evaluation of process is required which is only possible through optimization process [7]. Consider

$$
\mathrm{Fe}^{+2}+\mathrm{H}_{2} \mathrm{O}_{2} \longrightarrow \mathrm{Fe}^{+3}+\mathrm{HO}^{\bullet}+\mathrm{OH}^{-}
$$

In context to any engineering problem, optimization refers to improving the performance of system or process by applying several variables in different combinations to get the best possible result [8]. Optimization techniques are broadly classified into two categories: univariate and multivariate approach. Univariate approach, also known as one-factor-attime (OFAT) approach, involves variation of one parameter at a time. Nevertheless, multivariate approach has several advantages over OFAT. For example [9], (1) it provides global knowledge in its whole experimental domain while OFAT gives local knowledge where experiment is performed; (2) it is possible to study the interaction between the factors and nonlinear relationships with the responses, (3) the number of experiments required to optimize the process is considerably lesser than that of OFAT approach; (4) within the experimental domain at each point, quality of the information is higher and can be known through the leverage. The stepwise execution of optimization is presented in Figure 1.

Driven by the need of reducing the number of experiments, cost, time, and physical efforts, design of experiment (DOE) is an important statistical and mathematical tool for solving complex and multifactor engineering problems. 


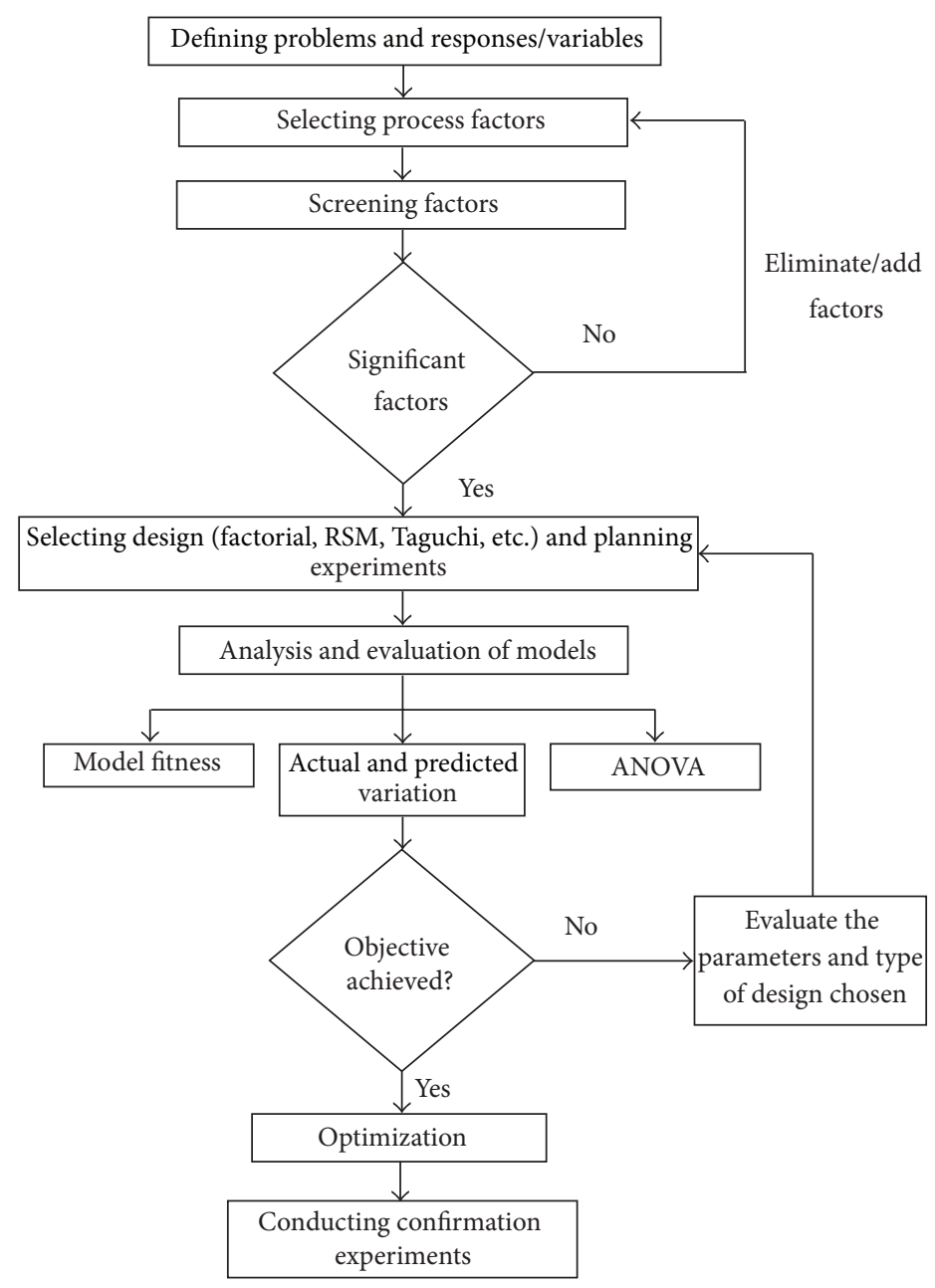

FIGURE 1: Flow chart for optimization.

It includes response surface methodology (RSM), factorial design, and in some special cases artificial neural network (ANN) [10]. However, central composite design (CCD), Doptimal, and Box-Behnken are found to be widely used optimization techniques for Fenton oxidation [11-13] because of the advantage of optimizing multifactor problems with optimum number of experimental runs. Besides, these methods have limitation of increased number of experiments if several factors were selected for process optimization. For example, Box-Behnken suggests 54 experiments if six factors are required to be studied and with CCD this number increases up to 80. Thus, with multiple factors these techniques are not appropriate because it increases the cost of chemicals, time, and physical efforts. Therefore, a simplified design strategy is required that can be used to overcome these problems.

Taguchi method is a robust statistical tool that allows the independent evaluation of the responses with minimum number of experiments. It employs orthogonal arrays for experimental design and $S / N$ ratio instead of responses itself to determine the optimum settings of control factors and thus neglects the variations caused by uncontrollable factors [14]. With this method, experimental results can be analyzed through $S / N$ ratio and ANOVA with simultaneously evaluating the significance of the factors in terms of their contribution to the response values.

Available works on optimization of Fenton oxidation mainly focus on CCD under RSM [15-17]. Nevertheless, fewer studies based on Taguchi method are found in the literature [18-20] but which technique is better for Fenton oxidation is still not inclusive. Therefore, this study was planned to compare two experimental design techniques and Fenton oxidation with four parameters such as [pollutants] $]_{\text {ini }}$, Dye : $\mathrm{Fe}^{+2}, \mathrm{H}_{2} \mathrm{O}_{2}: \mathrm{Fe}^{+2}$, and $\mathrm{pH}$ was selected as a case study. For comparison, frequently used CCD and robust Taguchi experimental design technique were chosen with a special focus on comparing the optimization and detailed statistical analysis of the experimental results.

\section{Background}

2.1. Response Surface Methodology and Central Composite Design. RSM, a multivariate statistical tool, consists of a group of mathematical and statistical techniques that are based on the fit of empirical models to the experimental 


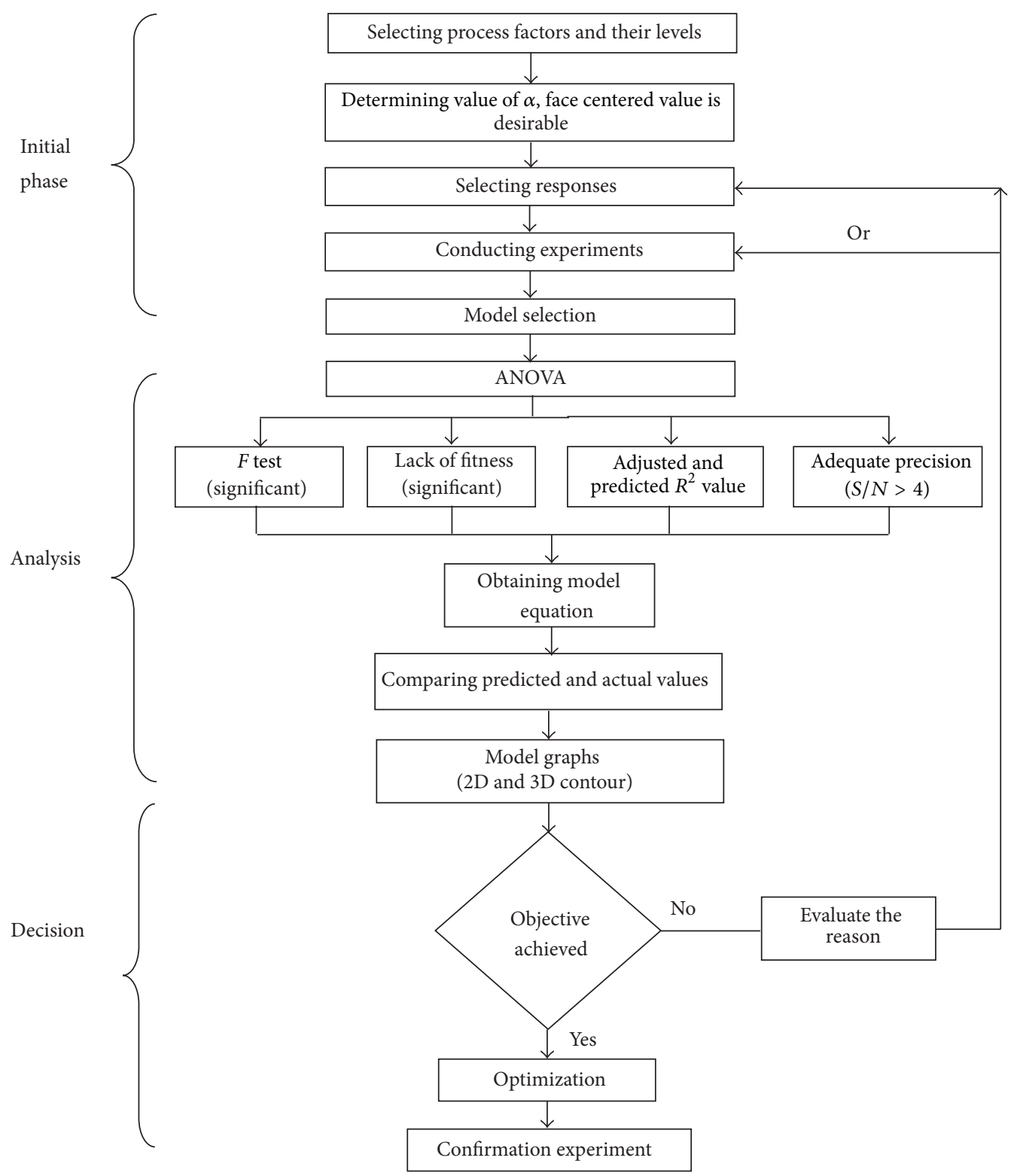

FIgURE 2: Central composite design flow diagram.

data obtained in relation to experimental design [21]. It employs lower order polynomial [22] and it has already been proved to be a reliable statistical method for chemical process applications $[23,24]$.

In RSM category, CCD which is appropriate for fitting second order polynomial equations has been frequently discussed for optimizing several research problems. A CCD has three groups of design points [25]:

(a) two-level factorial or fractional factorial design points $\left(2^{k}\right)$, consisting of possible combinations of +1 and -1 levels of factor;

(b) $2 k$ axial points (sometimes called star points) fixed axially at a distance say $\alpha$ from the center to generate quadratic terms; (c) center points which represent replicate terms; center points provide a good and independent estimate of the experimental error.

Considering these points, the number of experiments designed by CCD will be

$$
N=k^{2}+2 k+n,
$$

where $N$ is the total number of experiments, $k$ is the number of factors studied, and $n$ is the number of replicates. Central composite design under RSM is normally performed either by using design expert software or Minitab. In this study, design expert (Version: 8.0.7.1) is used as optimization software. The steps that will be followed for the central composite design (CCD) are presented in Figure 2. 
In CCD, value of alpha is important to calculate as it could determine the location of axial points in experimental domain. Depending on alpha value, design is spherical, orthogonal, rotatable, or face centered. Practically, it is in between face centered and spherical and is calculated as

$$
\alpha=\left(2^{k}\right)^{0.25} \text {. }
$$

Value of alpha equals 1 is desirable because it ensures the position of axial point within factorial portion region. It is called face centered design and offers three levels for the factors to be put in the experimental design matrix.

Experimental results obtained are analyzed using response surface regression procedure of statistical analysis system. Corelation between responses and independent variables is obtained by fitting them into second order polynomial equation [10]

$$
Y=\beta_{0}+\sum_{i=1}^{k} \beta_{i} x_{i}+\sum_{i=1}^{k} \beta_{i i} x_{i i}^{2}+\sum_{i=1}^{k} \sum_{i \neq j=1}^{k} \beta_{i j} x_{i} x_{j}+\varepsilon
$$

Here, $Y$ represents the responses, $k$ is the total number independent factors, $\beta_{0}$ is an intercept, $i$, $i$, and $i j$ with $\beta$ represent the coefficient values for linear, quadratic, and interaction effects, respectively, and $x_{i}$ and $x_{j}$ in the above equation show the coded levels for independent variables [26].

2.2. Taguchi Method and Signal to Noise Ratio. Taguchi method is a robust and multiparameter optimization statistical technique which employs fewer numbers of experiments to identify and optimize parameters to achieve desired response [27, 28]. It is a simple and systematic way of determining the effect of factors on responses and optimum condition of the factors. Taguchi method utilizes full fractional design called orthogonal arrays and ANOVA as a tool for analysis [29]. Orthogonal arrays are the minimum set of experiments which represents the various combinations of factors. Output of the orthogonal arrays is optimized with respect to signal to noise ratio $(S / N)$ of the responses instead of the responses itself and thus it reduces the process variability [30]. This feature marks the difference between the conventional statistical technique and Taguchi method. The stepwise procedure for Taguchi method is represented in Figure 3.

In Taguchi method, $S / N$ ratio is the measure of the deviation of the response from the desired value. Here, "signal" implies the mean value while "noise" shows the standard deviation term. It means that lower variability in the process is ensured through maximizing the $S / N$ ratio. However, depending on the type of response desired, Taguchi classified $S / N$ ratio into three categories: smaller-the-better, larger-the-better, and nominal-the-better [31]:

Smaller is better:

$$
S / N=-10 \log \left(\frac{1}{n} \sum_{k=1}^{n} y_{i}^{2}\right)
$$

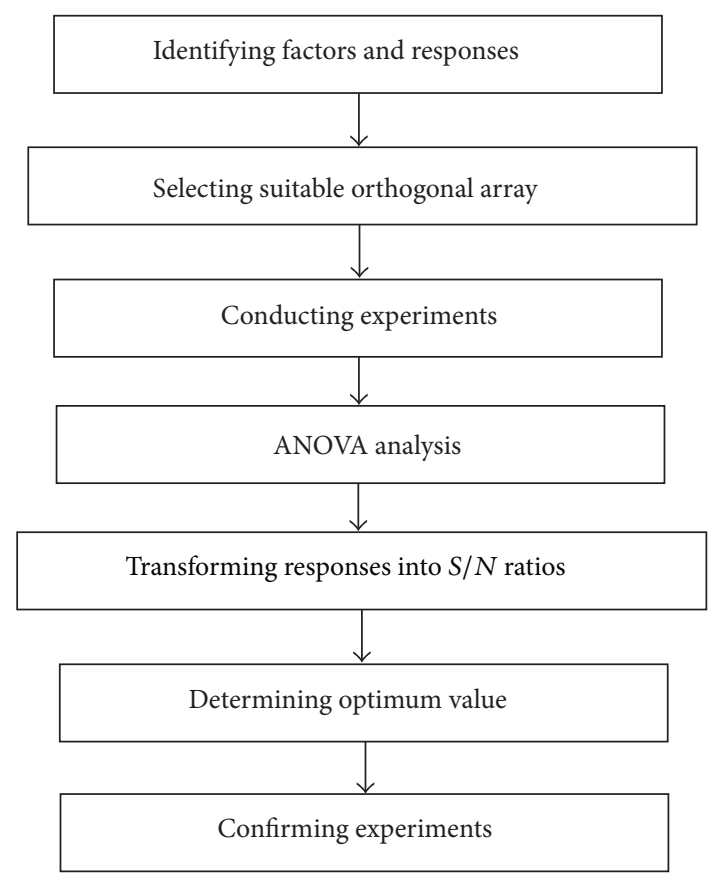

FIGURE 3: Taguchi orthogonal array.

Smaller is better:

$$
S / N=-10 \log \left(\frac{1}{n} \sum_{k=1}^{n} y_{i}^{2}\right) .
$$

Larger is better:

$$
S / N=-10 \log \left(\frac{1}{n} \sum_{k=1}^{n} \frac{1}{y_{i}^{2}}\right) .
$$

Nominal is better:

$$
S / N=-10 \log \left(\frac{1}{n} \sum_{k=1}^{n} \frac{\mu^{2}}{\sigma^{2}}\right),
$$

where $\mu=(1 / n) \sum_{k=1}^{n} y_{i} ; \sigma^{2}=(1 /(n-1)) \sum_{k=1}^{n}\left(y_{i}-\mu\right)^{2}$.

And $y_{i}$ represents response variables and " $n$ " donates the number of experiments.

One of the distinct features of Taguchi method is that it determines optimum value in the form of $S / N$ ratio. The predicted $S / N$ ratio at optimal process conditions can be computed by the following mathematical equation [32]:

$$
S / N_{\text {predicted }}=\bar{S} / N+\sum\left(S / N_{j}-\bar{S} / N\right),
$$

where $\bar{S} / N$ shows the mean of all $S / N$ ratios, $S / N_{j}$ is the $S / N$ ratio at the optimal level for each parameters, and $n$ is the number of process parameters that significantly affect the process.

\section{Case Study}

In this study, Fenton oxidation of synthetic dye acid blue 113 has been taken as a case study for comparing two optimization techniques, that is, CCD and Taguchi method. 
3.1. Experimental Details. For performing Fenton oxidation, all reagents used were of analytical grade and procured from Merck Sdn Bhd, Malaysia. Synthetic dye acid blue 113 was purchased from Sigma-Aldrich (M) Sdn Bhd, Malaysia.

For performing Fenton oxidation, stock solutions of $33.3 \mathrm{~g} / \mathrm{L}$ of $\mathrm{H}_{2} \mathrm{O}_{2}$ and $100 \mathrm{~g} / \mathrm{L}$ of $\mathrm{FeSO}_{4} \cdot 7 \mathrm{H}_{2} \mathrm{O}$ were prepared. All solutions were prepared by using distilled water. Fenton oxidation experiments were performed in batch laboratory scale Erlenmeyer flask (500 mL capacity) equipped with a magnetic stirrer. For each test, $150 \mathrm{~mL}$ of acid blue 113 dye solution was placed into flask and $\mathrm{pH}$ was adjusted by using $0.5 \mathrm{M} \mathrm{H}_{2} \mathrm{SO}_{4}$ or $1 \mathrm{M} \mathrm{NaOH}$ solution according to the designed experiment. Desired amounts of $\mathrm{FeSO}_{4} \cdot 7 \mathrm{H}_{2} \mathrm{O}$ and $\mathrm{H}_{2} \mathrm{O}_{2}$ solutions were added to the dye solution, respectively, while stirring at $150 \mathrm{rpm}$. The start time was recorded when $\mathrm{H}_{2} \mathrm{O}_{2}$ solution was added. After 90 minutes, $\mathrm{pH}$ of the solution was measured and sufficient amount of $1 \mathrm{M} \mathrm{NaOH}$ solution was added to increase $\mathrm{pH}$ above 11 to stop the reaction. This is because in alkaline conditions $\mathrm{Fe}^{+2}$ precipitates out as $\mathrm{Fe}^{+3}$ and $\mathrm{H}_{2} \mathrm{O}_{2}$ decomposes into oxygen. Then, after $2 \mathrm{hrs}$ of settling time, the supernatant was filtered through $0.45 \mu \mathrm{m}$ Millipore filter and subjected to various analyses. All experiments were performed at room temperature and atmospheric pressure.

3.2. Analysis. $\mathrm{pH}$ measurements of the solution were carried out with the aid of $\mathrm{pH}$ meter (CyberScan $\mathrm{pH}$ 300, Eutectic instruments). Quantitative measurement of the residual $\mathrm{H}_{2} \mathrm{O}_{2}$ in treated wastewater was carried out by using peroxide test strips (Merck). The raw and treated samples were scanned using UV-spectrophotometer (Spectroquant Pharo 300, Merck). And decolorization efficiency of the treated sample was calculated as follows:

$$
\text { Decolorization }(\%)=\left(1-\frac{\mathrm{Abs}_{f}}{\mathrm{Abs}_{\circ}}\right) \times 100 \text {. }
$$

COD measurements were made according to the standard method (APHA, AWWA, and WFE, 1998). For this, COD test cell supplied by Merck was heated in thermoreactor (Spectroquant TR 420) after adding required amount of the sample followed by the subsequent measurement in UVspectrophotometer according to the standard method. And COD removal efficiency is calculated as

$$
\operatorname{COD}(\%)=\left(1-\frac{\mathrm{COD}_{f}}{\mathrm{COD}_{\circ}}\right) \times 100 .
$$

\section{Result and Discussion}

4.1. Central Composite Design. All experiments for Fenton oxidation were designed according to RSM using central composite design (CCD) with the aid of design expert (Version: 8.0.7.1). According to the literature review, the most important parameters, which affect the efficiency of Fenton process, are $\mathrm{pH}$, initial concentrations of Dye, $\mathrm{Fe}^{+2}$, and $\mathrm{H}_{2} \mathrm{O}_{2}$ $[4,33,34]$. Therefore, [Dye] $]_{\text {ini }}, \mathrm{pH}, \mathrm{H}_{2} \mathrm{O}_{2}: \mathrm{Fe}^{+2}$ (wt/wt), and Dye : $\mathrm{Fe}^{+2}$ (wt/wt) ratios were chosen as control variables to be optimized using CCD as given in Table 1.
TABLE 1: Experimental range and levels of process variables.

\begin{tabular}{lccc}
\hline $\begin{array}{l}\text { Independent numerical } \\
\text { variables }\end{array}$ & Coded & $\begin{array}{c}\text { Low actual } \\
\text { value }\end{array}$ & $\begin{array}{c}\text { High actual } \\
\text { value }\end{array}$ \\
\hline Dye $(\mathrm{mg} / \mathrm{L})$ & $X_{1}$ & 100 & 300 \\
$\mathrm{H}_{2} \mathrm{O}_{2}: \mathrm{Fe}^{+2}(\mathrm{wt} / \mathrm{wt})$ & $X_{2}$ & 5 & 25 \\
$\mathrm{Dye}: \mathrm{Fe}^{+2}(\mathrm{wt} / \mathrm{wt})$ & $X_{3}$ & 10 & 50 \\
$\mathrm{pH}$ & $X_{4}$ & 2 & 9 \\
\hline
\end{tabular}

Total 30 runs with 16 factorial, 8 Axial, and 6 center points were suggested by design expert to optimize the responses, that is, COD and decolorization efficiency. Based on the proposed model, the following quadratic equation was developed to predict the dependent variables (responses) in terms of independent variables and their interactions:

$$
\begin{aligned}
Y= & b_{0}+b_{1} x_{1}+b_{2} x_{2}+b_{3} x_{3}+b_{4} x_{4}+b_{11} x_{1}{ }^{2}+b_{22} x_{2}{ }^{2} \\
& +b_{33} x_{3}{ }^{2}+b_{4} x_{4}{ }^{2}+b_{12} x_{1} x_{2}+b_{13} x_{1} x_{3}+b_{14} x_{1} x_{4} \\
& +b_{23} x_{2} x_{3}+b_{24} x_{2} x_{4}+b_{34} x_{3} x_{4},
\end{aligned}
$$

where $Y$ is the response variable (COD removal or decolorization efficiency), $b_{0}$ is constant, $b_{1}, b_{2}, b_{3}$, and $b_{4}$ are coefficient for linear effects, $b_{11}, b_{22}, b_{33}$, and $b_{44}$ are quadratic coefficient, and $b_{12}, b_{13}, b_{14}, b_{23}, b_{24}$, and $b_{34}$ are interaction coefficients [36], respectively.

\subsection{Model Results for Fenton Oxidation of Acid Blue 113}

4.2.1. Model Fitting and Analysis of Variance (ANOVA). Different concentrations of C.I. acid blue dye 113 were prepared and Fenton oxidation was performed under different conditions according to the experimental runs as suggested by CCD model. Based on experimental results, the following empirical second order polynomial equations were developed showing the interactions between the proposed independent variables to obtain decolorization and COD removal efficiencies:

$$
\begin{aligned}
\mathrm{COD}= & 64.18620-0.20098 *(\text { Dye })+0.70063 \\
& *\left(\mathrm{H}_{2} \mathrm{O}_{2}: \mathrm{Fe}^{+2}\right)+1.75866 *\left(\text { Dye }: \mathrm{Fe}^{+2}\right) \\
& * 0.42339 *(\mathrm{pH})+3.48465 E-003 \\
& *\left(\text { Dye } * \text { Dye }: \mathrm{Fe}^{+2}\right)-1.74043 E 003 \\
& *\left(\text { Dye } * \text { Dye }: \mathrm{Fe}^{+2}\right)+0.013948 *\left(\mathrm{Dye}^{+2} \mathrm{pH}\right) \\
& +0.031013 *\left(\mathrm{H}_{2} \mathrm{O}_{2}: \mathrm{Fe}^{+2}\right) *\left(\mathrm{Dye}: \mathrm{Fe}^{+2}\right) \\
& -0.13479 *\left(\mathrm{Dye}^{2} \mathrm{Fe}^{+2}\right) *(\mathrm{pH}) \\
& +3.88643 E-004 *\left(\mathrm{Dye}^{2}\right)-0.066812 \\
& *\left(\mathrm{H}_{2} \mathrm{O}_{2}:\left(\mathrm{Fe}^{+2}\right)^{2}\right)-0.021456 *\left(\mathrm{Dye}^{2}\left(\mathrm{Fe}^{+2}\right)^{2}\right)
\end{aligned}
$$


TABLE 2: Experimental design matrix, experimental runs, and predicted values on COD removal and decolorization efficiency.

\begin{tabular}{|c|c|c|c|c|c|c|c|c|}
\hline \multirow[b]{3}{*}{ Run } & \multirow[b]{3}{*}{ Dye $(\mathrm{mg} / \mathrm{L})$} & \multirow{2}{*}{\multicolumn{3}{|c|}{ Independent variables $(X)$}} & \multicolumn{4}{|c|}{ Dependent variables $(Y ;(\%))$} \\
\hline & & & & & \multicolumn{2}{|c|}{ Actual values } & \multicolumn{2}{|c|}{ Predicted values } \\
\hline & & $\mathrm{H}_{2} \mathrm{O}_{2}: \mathrm{Fe}^{+2}(\mathrm{wt} / \mathrm{wt})$ & Dye : $\mathrm{Fe}^{+2}$ (wt/wt) & $\mathrm{pH}$ & COD $(\%)$ & Decolorization (\%) & COD (\%) & Decolorization (\%) \\
\hline 1 & 200 & 15 & 30 & 5.5 & 75.3 & 95.4 & 73.2 & 95.1 \\
\hline 2 & 200 & 15 & 30 & 5.5 & 76.4 & 95.4 & 73.2 & 95.1 \\
\hline 3 & 300 & 25 & 50 & 9 & 62.8 & 96.8 & 60.9 & 95.7 \\
\hline 4 & 200 & 25 & 30 & 5.5 & 73.4 & 98.1 & 69.8 & 97.5 \\
\hline 5 & 300 & 5 & 50 & 9 & 34.8 & 80.0 & 35.1 & 79.8 \\
\hline 6 & 200 & 15 & 30 & 5.5 & 73.4 & 95.5 & 73.2 & 95.1 \\
\hline 7 & 100 & 5 & 10 & 9 & 66.5 & 55.8 & 63.4 & 59.7 \\
\hline 8 & 100 & 25 & 50 & 2 & 87.7 & 99.2 & 85.3 & 100.0 \\
\hline 9 & 200 & 15 & 30 & 9 & 65.8 & 78.9 & 67.3 & 80.3 \\
\hline 10 & 300 & 15 & 30 & 5.5 & 78.3 & 94.5 & 80.2 & 98.6 \\
\hline 11 & 100 & 15 & 30 & 5.5 & 77.1 & 90.1 & 73.9 & 86.7 \\
\hline 12 & 100 & 5 & 10 & 2 & 67.0 & 93.4 & 66.1 & 92.2 \\
\hline 13 & 100 & 5 & 50 & 9 & 30.2 & 56.1 & 32.9 & 54.4 \\
\hline 14 & 200 & 15 & 30 & 5.5 & 74.5 & 95.4 & 73.2 & 95.1 \\
\hline 15 & 300 & 5 & 10 & 9 & 77.9 & 89.1 & 79.4 & 85.9 \\
\hline 16 & 200 & 5 & 30 & 5.5 & 60.8 & 84.3 & 63.3 & 85.6 \\
\hline 17 & 100 & 25 & 10 & 9 & 48.0 & 67.9 & 50.51 & 65.1 \\
\hline 18 & 200 & 15 & 30 & 5.5 & 70.3 & 94.6 & 73.20 & 95.1 \\
\hline 19 & 300 & 25 & 10 & 2 & 67.4 & 98.9 & 63.6 & 98.3 \\
\hline 20 & 300 & 5 & 10 & 2 & 61.4 & 95.2 & 62.5 & 95.6 \\
\hline 21 & 100 & 25 & 10 & 2 & 50.3 & 97.6 & 53.1 & 99.9 \\
\hline 22 & 200 & 15 & 10 & 5.5 & 67.7 & 98.2 & 67.7 & 97.7 \\
\hline 23 & 300 & 25 & 10 & 9 & 80.4 & 84.4 & 80.5 & 86.3 \\
\hline 24 & 300 & 25 & 50 & 2 & 75.5 & 99.4 & 81.8 & 97.7 \\
\hline 25 & 200 & 15 & 30 & 2 & 74.1 & 98.3 & 79.1 & 97.5 \\
\hline 26 & 100 & 25 & 50 & 9 & 44.7 & 73.6 & 44.9 & 75.4 \\
\hline 27 & 200 & 15 & 50 & 5.5 & 62.7 & 93.5 & 61.6 & 94.7 \\
\hline 28 & 200 & 15 & 30 & 5.5 & 73.4 & 96.6 & 73.2 & 95.1 \\
\hline 29 & 100 & 5 & 50 & 2 & 72.1 & 76.5 & 73.4 & 76.7 \\
\hline 30 & 300 & 5 & 50 & 2 & 61.2 & 78.9 & 55.9 & 79.4 \\
\hline
\end{tabular}

Decolorization

$$
\begin{aligned}
= & 85.85276+0.092035 *(\text { Dye })+1.43440 \\
& *\left(\mathrm{H}_{2} \mathrm{O}_{2}: \mathrm{Fe}^{+2}\right)-0.70074 *\left(\text { Dye }: \mathrm{Fe}^{+2}\right) \\
& -0.97745 * \mathrm{pH}-1.26375 E-003 \\
& *\left(\text { Dye } * \mathrm{H}_{2} \mathrm{O}_{2}: \mathrm{Fe}^{+2}\right)-1.01250 E-004 \\
& *\left(\text { Dye } * \text { Dye }: \mathrm{Fe}^{+2}\right)+0.016293 *(\text { Dye } * \mathrm{pH}) \\
& +0.019450 *\left(\mathrm{H}_{2} \mathrm{O}_{2}: \mathrm{Fe}^{+2}\right) *\left(\mathrm{Dye}: \mathrm{Fe}^{+2}\right) \\
& -0.016857 *\left(\mathrm{H}_{2} \mathrm{O}_{2}: \mathrm{Fe}^{+2}\right) *(\mathrm{pH})+0.036054 \\
& *\left(\text { Dye }: \mathrm{Fe}^{+2}\right) *(\mathrm{pH})-2.50533 E-004
\end{aligned}
$$

$$
\begin{aligned}
& *\left(\text { Dye }^{2}\right)-0.036003 *\left(\mathrm{H}_{2} \mathrm{O}_{2}:\left(\mathrm{Fe}^{+2}\right)^{2}\right) \\
& -0.50615 *\left(\mathrm{pH}^{2}\right) .
\end{aligned}
$$

The objective of this empirical model was to adequately describe the interaction of factors influencing the process efficiency at the concentration ranges investigated. Experimental and predicted values on COD removal and decolorization efficiencies are provided in Table 2. The observed COD removal and decolorization values vary between $30.2-87.7 \%$ and 56.1-99.23\% which are in good agreement with the predicted values as shown in Figure 4.

Mathematical equation developed after fitting the function to the data may give misleading results and cannot describe the domain of the model adequately [37]. That is 


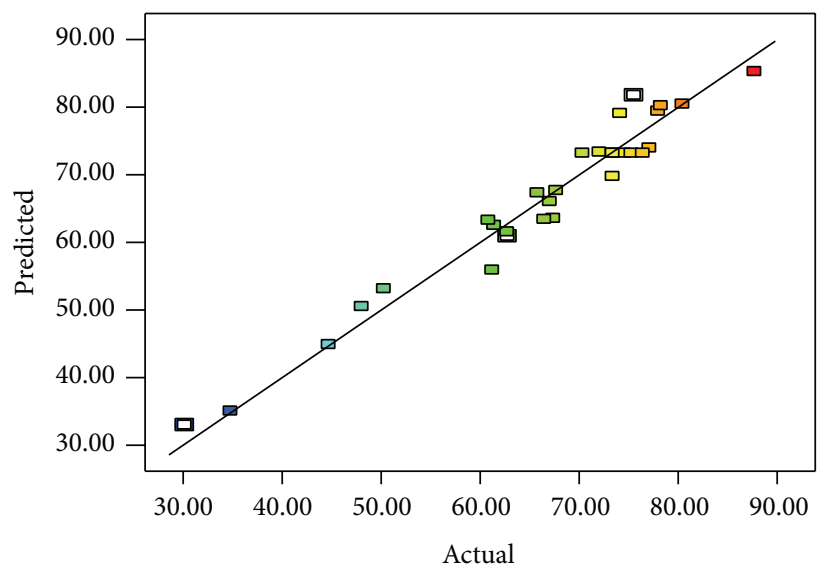

(a)

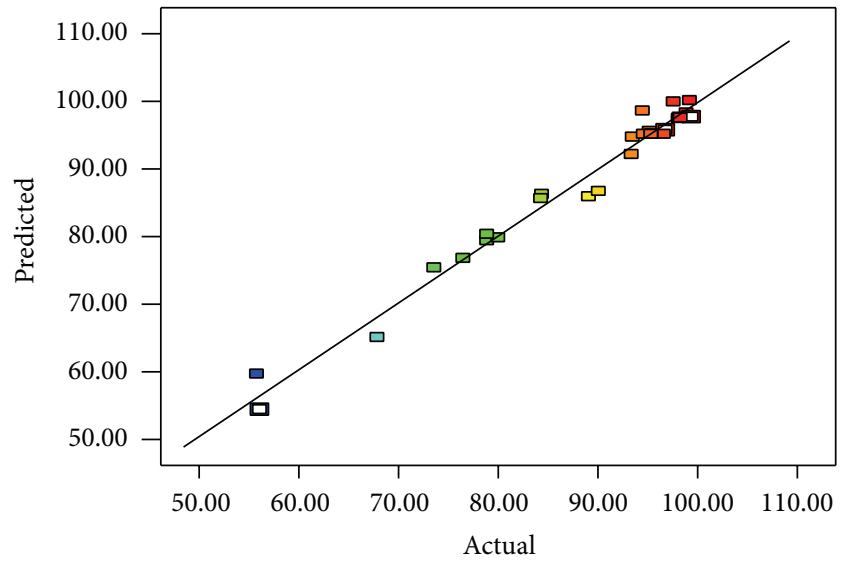

(b)

FIGURE 4: Predicted and actual value for (a) COD and (b) decolorization efficiency.

TABLE 3: ANOVA results for CCD.

\begin{tabular}{|c|c|c|c|c|c|}
\hline Source & Sum of squares & Degree of freedom & Mean square & $F$ value & Prob $>F$ \\
\hline \multicolumn{6}{|l|}{ COD removal } \\
\hline Model & 4902.21 & 12 & 408.52 & 32.41 & $\begin{array}{c}<0.0001 \\
\text { (significant) }\end{array}$ \\
\hline Dye & 173.73 & 1 & 173.73 & 32.41 & 0.0017 \\
\hline $\mathrm{H}_{2} \mathrm{O}_{2}: \mathrm{Fe}^{+2}$ & 188.48 & 1 & 188.48 & 13.94 & 0.0012 \\
\hline Dye $: \mathrm{Fe}^{+2}$ & 168.36 & 1 & 168.36 & 14.95 & 0.002 \\
\hline $\mathrm{pH}$ & 620.39 & 1 & 620.39 & 13.36 & $<0.0001$ \\
\hline \multicolumn{6}{|l|}{ Color Removal } \\
\hline Model & 4310.88 & 14 & 307.92 & 49.73 & $\begin{array}{c}<0.0001 \\
\text { (significant) }\end{array}$ \\
\hline Dye & 635.94 & 1 & 635.94 & 102.70 & $<0.0001$ \\
\hline $\mathrm{H}_{2} \mathrm{O}_{2}: \mathrm{Fe}^{+2}$ & 631.55 & 1 & 631.55 & 102 & $<0.0001$ \\
\hline Dye $: \mathrm{Fe}^{+2}$ & 38.90 & 1 & 38.90 & 6.28 & 0.0242 \\
\hline $\mathrm{pH}$ & 1331.97 & 1 & 1331.97 & 215.12 & $<0.0001$ \\
\hline
\end{tabular}

why ANOVA is an integral part of the data analysis and is the more reliable way to evaluate the quality of the model fitted [21]. Table 3 shows the analysis of variance for COD and color removal efficiency.

Values of Prob $>F$ less than 0.0500 imply that the model terms are significant while values greater than 0.1000 are demonstrated as insignificant for the regression model. In the current study, $F$ values 32.41 and 49.73 for COD and color removal denote the model as significant. The goodness of the fit of the model is also checked by $R^{2}$ value. In both cases, the values for this regression coefficient were 0.9789 and 0.9581 which implies that this model is statistically significant and is in reasonable agreement with the adjusted $R^{2}$. Moreover, "Adeq precision" is used to determine the signal to noise $(S / N)$ ratio to determine the validity of the model. A ratio greater than 4 is recommended. In our case, $S / N$ values of 25.9 and 22.3 for color and COD removal indicate an adequate signal. They also show that this model can be used to navigate the design space. Another checkpoint for validating the experimental data is the analysis of normal probability plots. The normal probability plot indicates whether the residuals follow a normal distribution, in which case the points will follow a straight line, as it is in the current study (Figures A.1 and A.2 in Supplementary Material available online at http://dx.doi.org/10.1155/2014/869120). Considering the above explained ANOVA results, it can be concluded that this model explained the Fenton reaction and can be employed to navigate the design space in terms of decolorization and COD removal efficiencies.

\subsubsection{Response Surface Plotting and Optimization of Operating} Parameters. Graphical interpretation of interactions by using three and two dimensional plots of regression model is highly recommended and is used to assess the interactive effects between the process variables and treatment efficiencies of Fenton process [38-40]. The surface response plots of COD and color removal efficiencies of Fenton reaction regarding interaction effects between dye concentration and other 


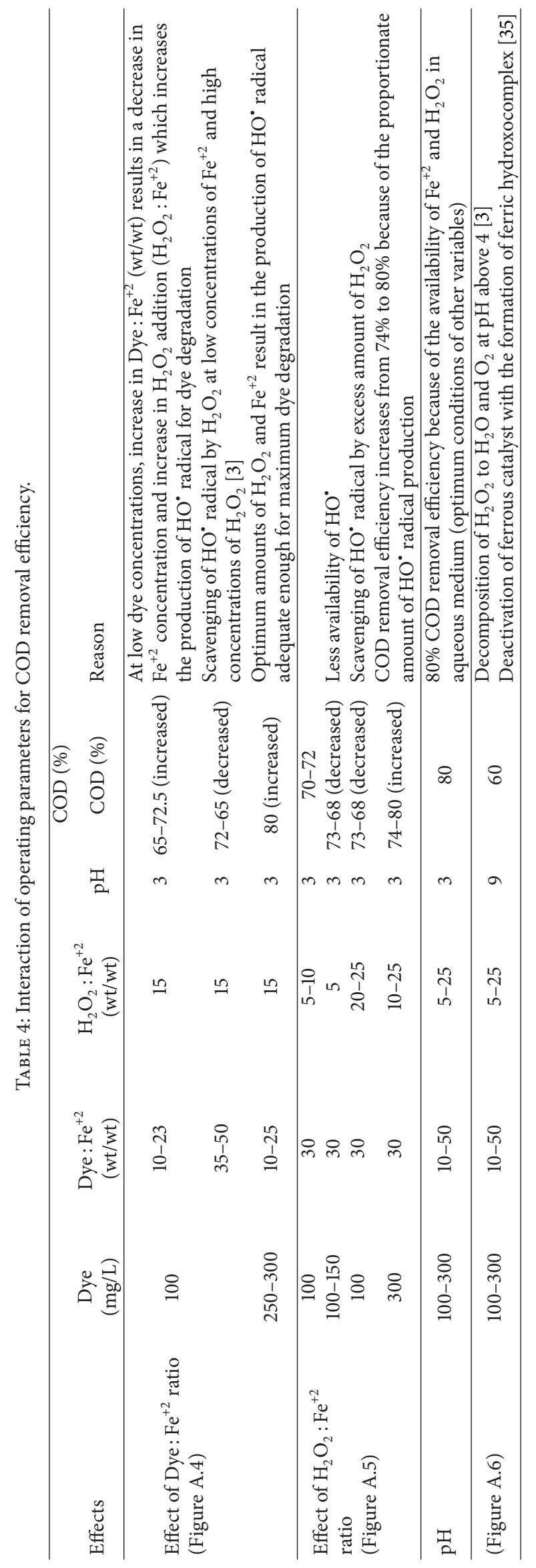


TABLE 5: Optimized operating parameters.

\begin{tabular}{lcccccc}
\hline Dye $(\mathrm{mg} / \mathrm{L})$ & Dye $: \mathrm{Fe}^{+2}(\mathrm{wt} / \mathrm{wt})$ & $\mathrm{H}_{2} \mathrm{O}_{2}: \mathrm{Fe}^{+2}(\mathrm{wt} / \mathrm{wt})$ & $\mathrm{pH}$ & $\mathrm{COD}(\%)$ & $\begin{array}{c}\text { Predicted responses } \\
\text { Decolorization }(\%)\end{array}$ & Desirability \\
\hline 300 & 25.92 & 19.15 & 3 & 81.64 & 99.40 & 0.972 \\
\hline
\end{tabular}

selected independent variables are presented in supplementary data in Figures A.3-A.6.

The interaction for assessing decolorization efficiency implies that Dye $/ \mathrm{Fe}^{+2}$ and $\mathrm{H}_{2} \mathrm{O}_{2} / \mathrm{Fe}^{+2}$ have proportional effect on color removal efficiency. It can be seen from the plots that there is an increase in decolorization efficiency with increase in control variables and dye concentration. The reason for this increasing trend is that $\mathrm{HO}^{*}$ radically produced is reactive enough for the cleavage of the Azo bonds $(-\mathrm{N}=\mathrm{N}-)$ and at high values of $\mathrm{H}_{2} \mathrm{O}_{2} / \mathrm{Fe}^{+2}$ and $\mathrm{Dye} / \mathrm{Fe}^{+2}$, higher concentrations of $\mathrm{HO}^{\circ}$ radical are available to react with the high concentration of dye [33]. In this study, 95\% decolorization of acid blue dye was observed within 10 minutes of reaction time under optimum conditions. And over $90 \%$ of the color removal was observed for most of the treated samples. However, from data available in Table 2 and contour plots (Figure A.3), it was found that $\mathrm{pH}$ exhibits inverse relationship with dye decolorization efficiency. This is because at higher $\mathrm{pH}$ values, decomposition of $\mathrm{H}_{2} \mathrm{O}_{2}$ to oxygen and conversion of ferrous ions to ferric hydroxocomplex take place which will in turn make $\mathrm{HO}^{\circ}$ radical unavailable for the reaction to take place [41].

From aforementioned discussion, it is confirmed that Fenton's reagents are active for decolorization. However, efficient degradation of dye is difficult to achieve and it requires optimization of the Fenton oxidation. Unlike decolorization, concentration of Fenton's reagents is not directly linked with COD removal efficiency. In order to make things understandable and comparable, a detailed analysis of the effect of Fenton's reagent on COD removal efficiency is presented in Table 4. Moreover, three- and two-dimensional contour plots obtained by CCD model are also provided in supplementary data (Figures A.4-A.6).

Optimization study of the experimental results was performed by keeping all responses within desired ranges by using response surface methodology. In present studies, dye concentration was targeted to the maximum and other variables were kept in range. Based on the suggested values as given in Table 5, experiment was conducted to validate the optimized results. According to the results obtained approximately, $79.1 \%$ of the COD removal was achieved with $98.401 \%$ decolorization efficiency. This indicates a good agreement of the experimental and predicted results under optimized conditions. Comparison of the results with previously conducted studies indicates that efficiency of the process is improved in terms of both chemical consumptions and COD removal efficiency. For example, Meriç et al. [42] obtained $71 \%$ COD and $99 \%$ color removal at optimum conditions of $100 \mathrm{mg} / \mathrm{L}$ of $\mathrm{FeSO}_{4}$ and $400 \mathrm{mg} / \mathrm{L}$ of $\mathrm{H}_{2} \mathrm{O}_{2}$ for $100 \mathrm{mg} / \mathrm{L}$ of Reactive Black 5. In another study, $2000 \mathrm{mg} / \mathrm{L}$ of $\mathrm{H}_{2} \mathrm{O}_{2}$ and $200 \mathrm{mg} / \mathrm{L}$ of $\mathrm{FeSO}_{4}$ were used for $88 \%$ COD removal of $200 \mathrm{mg} / \mathrm{L}$ of Reactive Black 5 [43]. It implies that CCD under
TABLE 6: Factors and levels of orthogonal array.

\begin{tabular}{lccc}
\hline Parameters & Level 1 & Level 2 & Level 3 \\
\hline [Dye] & 100 & 200 & 300 \\
Dye $: \mathrm{Fe}^{+2}$ & 10 & 30 & 50 \\
$\mathrm{H}_{2} \mathrm{O}_{2}: \mathrm{Fe}^{+2}$ & 5 & 15 & 25 \\
$\mathrm{pH}$ & 2 & 5.5 & 9 \\
\hline
\end{tabular}

RSM is a suitable tool for optimizing Fenton treatment of the recalcitrant wastewater with improved efficiency and less consumption of chemicals.

\section{Taguchi Method}

5.1. Experimental Design. Taguchi method was used to determine the optimum conditions for Fenton oxidation and to make comparison with the results obtained with CCD. Minitab 16 was used for the orthogonal experimental design. Same as before, [Dye] $]_{\text {ini }}$, Dye/ $\mathrm{Fe}^{+2}$ (wt/wt), $\mathrm{H}_{2} \mathrm{O}_{2} / \mathrm{Fe}^{+2}$ (wt/wt), and $\mathrm{pH}$ were chosen as control factors for optimization through Taguchi orthogonal arrays experimental design. Each factor was varied at three levels (Table 6) and $L_{9}$ orthogonal array was selected to determine the optimal conditions with minimum number of experiments. The number of experiments required was reduced to 9 which was considerably lesser than that of CCD. It implies that only 9 experiments with different combination of parameters are required to study Fenton oxidation, which in conventional full factorial design would be $3^{4}=81$ experimental runs.

In second stage, experiments were performed and response values were obtained. For result analysis, Taguchi method follows entirely different steps in contrast to CCD. As followed by previous studies, response values were converted into $S / N$ ratio which was used to analyze the results [18, 19, 44-46]. For Fenton oxidation, maximum COD and color removal percentages are desired that is why "larger is better" $S / N$ ratio formula, as given by (3), was used to determine the $S / N$ value for each response. The experimental results and $S / N$ ratio for each run are given in Table 7.

In comparison to CCD, ranking of operating parameters in terms of contribution to response values is possible with Taguchi method. It also suggests the use of Taguchi method for screening the input variables during the initial stages of process investigation. In the current study, four parameters were selected and from Table 8, it is clear that for both types of responses $\mathrm{pH}$ was the most contributing factor. This observation was also confirmed from the literature that Fenton oxidation shows maximum efficiency at $\mathrm{pH} 3$ and deviation from this value decreases the efficiency of the process [41]. 
TABLE 7: $L_{9}$ orthogonal designs, Levels of four factors, and experimental results obtained.

\begin{tabular}{lccccccc}
\hline Dye $(\mathrm{mg} / \mathrm{L})$ & Dye $: \mathrm{Fe}^{+2}(\mathrm{wt} / \mathrm{wt})$ & $\mathrm{H}_{2} \mathrm{O}_{2}: \mathrm{Fe}^{+2}(\mathrm{wt} / \mathrm{wt})$ & $\mathrm{pH}$ & \multicolumn{2}{c}{ Actual values } & \multicolumn{2}{c}{$S / N$ ratio } \\
Decolorization
\end{tabular}

TABLE 8: Response table for signal to noise $(S / N)$ ratio.

\begin{tabular}{|c|c|c|c|c|}
\hline Level & Dye & Dye $: \mathrm{Fe}^{+2}$ (wt/wt) & $\mathrm{H}_{2} \mathrm{O}_{2}: \mathrm{Fe}^{+2}(\mathrm{wt} / \mathrm{wt})$ & $\mathrm{pH}$ \\
\hline \multicolumn{5}{|c|}{ COD removal } \\
\hline 1 & 34.72 & 35.06 & 33.87 & 37.96 \\
\hline 2 & 33.84 & 34.75 & 34.12 & 34.77 \\
\hline 3 & 34.94 & 33.69 & 35.52 & 30.77 \\
\hline Delta & 1.10 & 1.37 & 1.65 & 7.19 \\
\hline Rank & 4 & 3 & 2 & 1 \\
\hline \multicolumn{5}{|c|}{ Decolorization } \\
\hline 1 & 39.59 & 39.45 & 39.63 & 39.94 \\
\hline 2 & 39.28 & 39.76 & 39.42 & 39.75 \\
\hline 3 & 39.84 & 39.49 & 39.65 & 39.01 \\
\hline Delta & 0.56 & 0.32 & 0.23 & 0.93 \\
\hline Rank & 2 & 3 & 4 & 1 \\
\hline
\end{tabular}

5.2. Statistical Analysis. In CCD, analysis of variance (ANOVA) and regression models are used as evaluation criteria for the statistical analysis of the results. However, Taguchi method uses signal to noise ratio $(S / N)$ as a main approach for the analysis. Nevertheless, ANOVA can be employed for the evaluation of experimental results with a main objective of determining the contribution of each factor to variance of result. It is similar to regression analysis which is used to study and model the relationship between response and one or more independent variables [47].

Table 9 shows ANOVA results for both COD and color removal efficiency of acid blue 113 dye. From the table, it is clear that $\mathrm{pH}$ exhibits maximum contribution with percent contribution of $66.2 \%$ and $87.62 \%$ for both color and COD removal, respectively. It is also in agreement with the values reported in Table 8. Moreover, Sohrabi et al. [19] also reported $\mathrm{pH}$ to be the most significant factor (percent contribution: $84.90 \%$ ) while demonstrating Fenton and photo-Fenton process. This observation can be supported by the fact that, at high $\mathrm{pH}$ values, decomposition of $\mathrm{H}_{2} \mathrm{O}_{2}$ to oxygen and formation of hydroxocomplex take place which results in low efficiency of Fenton oxidation even at optimum conditions of Fenton's reagent [41]. Thus, with confidence level of 95\%, it has been confirmed that Taguchi method with minimum number of experiments can be used as an alternative to CCD for Fenton oxidation. In order to confirm it, optimized values for the responses were computed to countercheck it with that of CCD.

\subsection{Confirmation Test and Optimization of Operating Param-} eters by Taguchi Method. In Taguchi's method, confirmation test is important to verify the experimental results. However, this method has limitations for multiple response processes like Fenton oxidation. This is because unlike CCD it suggests individual sets of optimized parameters for individual responses. In the present case study, decolorization and COD removal efficiencies were selected as responses for determining the optimized set of the input variables. Figure 5 shows the best conditions for the Fenton oxidation. The highest $S / N$ ratios corresponding to the COD and color removal suggest the best levels for each of the parameters. It can be seen from the figure that $\mathrm{pH}$ shows the highest $S / N$ ratio for both COD and color removal efficiencies. Thus, it confirms the maximum contribution of $\mathrm{pH}$ to $\mathrm{COD}$ and color removal efficiencies.

Figure 5 shows the effect of operating parameters on $\mathrm{COD}$ and color removal efficiency in terms of $S / N$ ratio. The highest $S / N$ ratios corresponding to the COD and color removal is desirable and suggests the best levels for each of the parameters. In the present example, Dye $\left(L_{3}\right)$, Dye : Fe ${ }^{+2}\left(L_{1}\right)$, $\mathrm{H}_{2} \mathrm{O}_{2}: \mathrm{Fe}^{+2}\left(L_{3}\right)$, and $\mathrm{pH}\left(L_{1}\right)$ were optimized conditions for COD removal efficiency while Dye $\left(L_{3}\right)$, Dye : Fe ${ }^{+2}\left(L_{2}\right)$, $\mathrm{H}_{2} \mathrm{O}_{2}: \mathrm{Fe}^{+2}\left(L_{3}\right)$, and $\mathrm{pH}\left(L_{1}\right)$ were the optimized set for decolorization. Optimized values corresponding to these levels are given in Table 10.

Evaluation of operating parameters by using interaction plots indicates that dye concentration of $200 \mathrm{mg} / \mathrm{L}$ in different combinations with other parameters shows maximum COD and decolorization efficiency. The interaction plots were produced in Minitab and are provided in supplementary data in Figures A.7 and A.8. From the figures, it can be seen that $\mathrm{pH}$ at $L_{1}$ shows maximum efficiency for all combinations of operating parameters. However, dye concentration at $L_{2}$ in combination with Dye : $\mathrm{Fe}^{+2}$ of 30 showed $80 \%$ COD removal efficiency. Same results were obtained when $\mathrm{H}_{2} \mathrm{O}_{2}: \mathrm{Fe}^{+2}$ ratio was set at 25 . Similar trend was observed while studying the interactive effects of operating parameters for determining 
TABLE 9: ANOVA results.

\begin{tabular}{lcccccc}
\hline Factors & Degree of freedom & Sum of squares & Mean Square & $F$ ratio & $P$ value & Percent contribution (\%) \\
\hline COD $(\%)$ & & & & & & \\
$\quad$ Dye & 2 & 45 & 45 & 0.04 & 0.961 & 1.32 \\
Dye $: \mathrm{Fe}^{+2}$ & 2 & 167 & 167 & 0.15 & 0.860 & 4.89 \\
$\mathrm{H}_{2} \mathrm{O}_{2}: \mathrm{Fe}^{+2}$ & 2 & 211 & 211 & 0.20 & 0.826 & $6.17 \%$ \\
$\mathrm{pH}$ & 2 & 2995.3 & 2995.3 & 21.23 & 0.002 & 87.62 \\
Decolorization (\%) & & & & & & \\
Dye & 2 & 53.3 & 26.7 & 0.83 & 0.482 & 21.6 \\
Dye $: \mathrm{Fe}^{+2}$ & 2 & 18.8 & 9.4 & 0.25 & 0.789 & 7.61 \\
$\mathrm{H}_{2} \mathrm{O}_{2}: \mathrm{Fe}^{+2}$ & 2 & 9.6 & 4.8 & 0.12 & 0.888 & 3.87 \\
$\mathrm{pH}$ & 2 & 165.1 & 82.6 & 6.07 & 0.036 & 66.2 \\
\hline
\end{tabular}

decolorization efficiency and maximum 99\% decolorization efficiency was obtained. Comparison of the findings of the interactive plots of both types of statistical techniques showed that Taguchi method with simple graphical presentation can well explain the interaction of operating parameters. The results obtained were in good agreement with each other. Thus, Taguchi method can be used as a substitute for CCD for assessing the experimental results.

Predicted values of the responses for these optimized values can be computed by using (6). This equation considers only significant parameters. Although only $\mathrm{pH}$ is significant parameter according to ANOVA analysis, Dye, Dye: $\mathrm{Fe}^{+2}$, and $\mathrm{H}_{2} \mathrm{O}_{2}: \mathrm{Fe}^{+2}$ have to be optimized to maximize the COD removal and decolorization efficiency. The predicted $S / N$ ratios for optimized conditions were computed and obtained values were 37.96 and 39.94 for COD and color removal, respectively. The predicted and actual values obtained as a result of confirmation test are also given in Table 9. The predicted values obtained through Taguchi method were almost close to those obtained through CCD except $\mathrm{H}_{2} \mathrm{O}_{2}: \mathrm{Fe}^{+2}$ ratios. The $\mathrm{H}_{2} \mathrm{O}_{2}: \mathrm{Fe}^{+2}$ ratio is higher when compared to that obtained with CCD; the main reason for this is that with design expert, it is possible to select the desired range for experimental parameters. With $\mathrm{CCD}, \mathrm{H}_{2} \mathrm{O}_{2}: \mathrm{Fe}^{+2}$ ratio was selected as the lowest one. However, experimental results obtained under optimized conditions (Taguchi method) are close to predicted values as well as those obtained in CCD. This shows that for optimizing operating parameters for Fenton oxidation, Taguchi method is suitable and economical approach and can be used as a substitute to central composite design.

\section{Conclusion}

This study was planned to compare two optimization techniques such as central composite design and Taguchi orthogonal array and Fenton oxidation with four parameters; that is, [Dye $]_{\text {ini }}$, Dye $: \mathrm{Fe}^{+2}, \mathrm{H}_{2} \mathrm{O}_{2}: \mathrm{Fe}^{+2}$, and $\mathrm{pH}$ were selected as a case study. From this study, the following points can be drawn as conclusion.

(i) Taguchi method offered nine experiments for analyzing the Fenton oxidation process while CCD suggested 30 experiments. (ii) At optimized conditions, Fenton process would be able to achieve $81 \%$ and $79 \%$ COD removal efficiency and $99 \%$ decolorization efficiency for both CCD and Taguchi method, respectively.

(iii) $S / N$ ratios and ANOVA under Taguchi method showed $\mathrm{pH}$ to be the most contributed factor with percent contribution of $87.62 \%$ and $66.2 \%$ for COD and decolorization efficiency, respectively.

(iv) Interactive study of operating parameters by 3D contour plots produced by $\mathrm{CCD}$ also exhibits $\mathrm{pH}$ and $\mathrm{H}_{2} \mathrm{O}_{2}: \mathrm{Fe}^{+2}$ the most significant factors. However, quantification of contribution is not possible with CCD.

Thus, it can be concluded that Taguchi method is a robust statistical tool for experimental design and process optimization. Data analysis and optimization of operating parameters are possible with fewest numbers of experiments, less computational experience, and graphs obtained which are easy to read and understand. The optimized values obtained for both cases were in good agreement with each other which shows the potential of Taguchi method to be used in chemical engineering applications. Therefore, it can be concluded that it can be used as a substitute for central composite design for Fenton oxidation process.

\section{Abbreviations}

AOPs: Advance oxidation process

$\mathrm{Fe}^{+2}$ : $\quad$ Ferrous iron

$\mathrm{Fe}^{+3}: \quad$ Ferric iron

$\mathrm{H}_{2} \mathrm{O}_{2}$ : Hydrogen peroxide

$\mathrm{HO}^{\circ}$ : Hydroxyl radical

OFAT: One factor at time

DOE: Design of experiments

CCD: Central composite design

RSM: Response surface methodology

ANN: Artificial neural network

ANOVA: Analysis of variance

$S / N$ : Signal to noise ratio. 

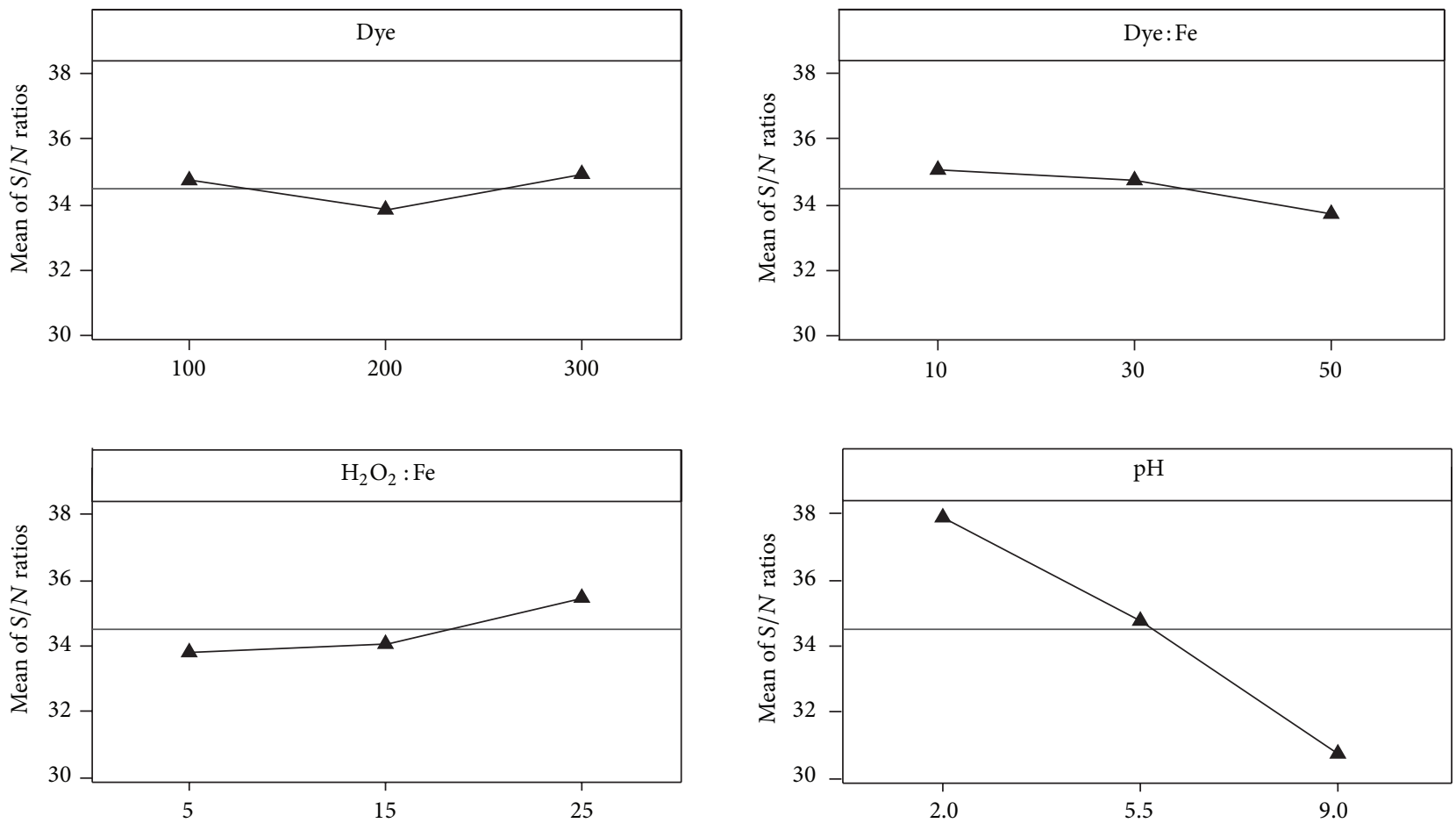

(a)
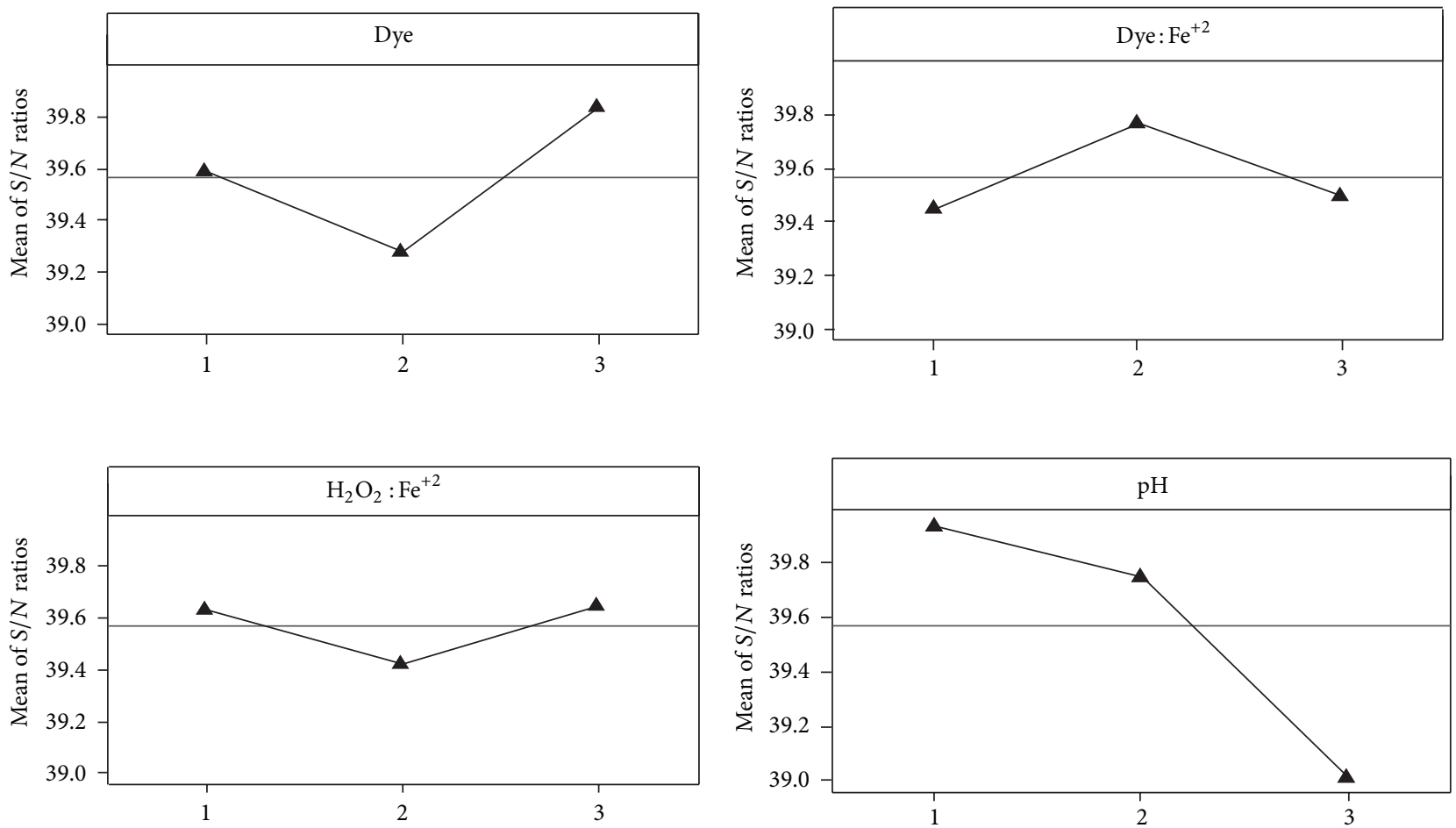

(b)

FIgure 5: Mean $S / N$ ratio for (a) COD removal and (b) decolorization.

TABLE 10: Optimized values for COD removal and decolorization.

\begin{tabular}{lcccccc}
\hline & Dye & Dye $: \mathrm{Fe}^{+2}$ & $\mathrm{H}_{2} \mathrm{O}_{2}: \mathrm{Fe}^{+2}$ & $\mathrm{pH}$ & Predicted & Actual \\
\hline COD removal & 300 & 10 & 25 & 3 & 79.06 & 81.2 \\
Decolorization & 300 & 15 & 25 & 3 & 99.31 & 99.04 \\
\hline
\end{tabular}




\section{Conflict of Interests}

The authors declare that there is no conflict of interests regarding the publication of this paper.

\section{Acknowledgments}

The authors are grateful to the Faculty of Engineering, University of Malaya, University of Malaya High Impact Research Grant (HIR-MOHE-D000037-16001) from the Ministry of Higher Education Malaysia, and University of Malaya Bright Sparks Unit which financially supported this work.

\section{References}

[1] R. Andreozzi, V. Caprio, A. Insola, and R. Marotta, "Advanced oxidation processes (AOP) for water purification and recovery," Catalysis Today, vol. 53, no. 1, pp. 51-59, 1999.

[2] L. Gomathi Devi, S. Girish Kumar, K. Mohan Reddy, and C. Munikrishnappa, "Photo degradation of Methyl Orange an azo dye by Advanced Fenton Process using zero valent metallic iron: Influence of various reaction parameters and its degradation mechanism," Journal of Hazardous Materials, vol. 164, no. 2-3, pp. 459-467, 2009.

[3] K. Ntampegliotis, A. Riga, V. Karayannis, V. Bontozoglou, and G. Papapolymerou, "Decolorization kinetics of Procion H-exl dyes from textile dyeing using Fenton-like reactions," Journal of Hazardous Materials, vol. 136, no. 1, pp. 75-84, 2006.

[4] B. H. Hameed and T. W. Lee, "Degradation of malachite green in aqueous solution by Fenton process," Journal of Hazardous Materials, vol. 164, no. 2-3, pp. 468-472, 2009.

[5] X. Zhu and B. E. Logan, "Using single-chamber microbial fuel cells as renewable power sources of electro-Fenton reactors for organic pollutant treatment," Journal of Hazardous Materials, vol. 252-253, pp. 198-203, 2013.

[6] B. H. Diya'uddeen, A. R. Abdul Aziz, and W. M. A. W. Daud, "On the limitation of Fenton oxidation operational parameters: a review," International Journal of Chemical Reactor Engineering, vol. 10, no. 1, article R2, 2012.

[7] A. Ellert and A. Grebe, "Process optimization made easy: design of experiments with multi-bioreactor system BIOSTAT Qplus," Nature Methods, vol. 8, no. 4, 2011.

[8] P. W. Araujo and R. G. Brereton, "Experimental design II. Optimization," TrAC Trends in Analytical Chemistry, vol. 15, no. 2, pp. 63-70, 1996.

[9] R. Leardi, "Experimental design in chemistry: a tutorial," Analytica Chimica Acta, vol. 652, no. 1-2, pp. 161-172, 2009.

[10] M. B. Kasiri, H. Aleboyeh, and A. Aleboyeh, "Modeling and optimization of heterogeneous photo-fenton process with response surface methodology and artificial neural networks," Environmental Science and Technology, vol. 42, no. 21, pp. 79707975, 2008.

[11] M. Azami, M. Bahram, and S. Nouri, "Central composite design for the optimization of removal of the azo dye, Methyl Red, from waste water using Fenton reaction," Current Chemistry Letters, vol. 2, no. 2, pp. 57-68, 2013.

[12] D. B. Hasan, A. R. A. Aziz, and W. M. A. Wan Daud, "Using D-optimal experimental design to optimise remazol black B mineralisation by Fenton-like peroxidation," Environmental Technology, vol. 33, no. 10, pp. 1111-1121, 2012.
[13] E. C. Catalkaya and F. Kargi, "Response surface analysis of photo-fenton oxidation of simazine," Water Environment Research, vol. 81, no. 7, pp. 735-742, 2009.

[14] T. J. S. Anand, "DOE based statistical approaches in modeling of laser processing-review and suggestion," International Journal of Engineering \& Technology IJET-IJENS, vol. 10, no. 4, pp. 1-7, 2010.

[15] L. A. Lu, Y. S. Ma, A. Daverey, and J. G. Lin, "Optimization of photo-Fenton process parameters on carbofuran degradation using central composite design," Journal of Environmental Science and Health - Part B Pesticides, Food Contaminants, and Agricultural Wastes, vol. 47, no. 6, pp. 553-561, 2012.

[16] F. Torrades, S. Saiz, and J. A. García-Hortal, "Using central composite experimental design to optimize the degradation of black liquor by Fenton reagent," Desalination, vol. 268, no. 1-3, pp. 97-102, 2011.

[17] A. Zuorro, M. Fidaleo, and R. Lavecchia, "Response surface methodology (RSM) analysis of photodegradation of sulfonated diazo dye Reactive Green 19 by $\mathrm{UV} / \mathrm{H}_{2} \mathrm{O}_{2}$ process," Journal of Environmental Management, vol. 127, pp. 28-35, 2013.

[18] T. C. Cheng, K. S. Yao, Y. H. Hsieh, L. L. Hsieh, and C. Y. Chang, "Optimizing preparation of the $\mathrm{TiO}_{2}$ thin film reactor using the Taguchi method," Materials and Design, vol. 31, no. 4, pp. 17491751, 2010.

[19] M. R. Sohrabi, A. Kavaran, S. Shariati, and S. Shariati, "Removal of Carmoisine edible dye by Fenton and photo Fenton processes using Taguchi orthogonal array design," Arabian Journal of Chemistry, 2014.

[20] K. C. Namkung, A. E. Burgess, D. H. Bremner, and H. Staines, "Advanced Fenton processing of aqueous phenol solutions: a continuous system study including sonication effects," Ultrasonics Sonochemistry, vol. 15, no. 3, pp. 171-176, 2008.

[21] M. A. Bezerra, R. E. Santelli, E. P. Oliveira, L. S. Villar, and L. A. Escaleira, "Response surface methodology (RSM) as a tool for optimization in analytical chemistry," Talanta, vol. 76, no. 5, pp. 965-977, 2008.

[22] L. Ye, M. Ying, L. Xu, C. Guo, L. Li, and D. Wang, "Optimization of inductive angle sensor using response surface methodology and finite element method," Measurement, vol. 48, pp. 252-262, 2014.

[23] T. Ölmez, "The optimization of $\mathrm{Cr}(\mathrm{VI})$ reduction and removal by electrocoagulation using response surface methodology," Journal of Hazardous Materials, vol. 162, no. 2-3, pp. 1371-1378, 2009.

[24] S. Baroutian, M. K. Aroua, A. A. A. Raman, and N. M. N. Sulaiman, "A packed bed membrane reactor for production of biodiesel using activated carbon supported catalyst," Bioresource Technology, vol. 102, no. 2, pp. 1095-1102, 2011.

[25] D. Montgomery, Design and Analysis of Experiments, John Wiley \& Sons, New York, NY, USA, 2001.

[26] A. El-Ghenymy, S. Garcia-Segura, R. M. Rodríguez, E. Brillas, M. S. El Begrani, and B. A. Abdelouahid, "Optimization of the electro-Fenton and solar photoelectro-Fenton treatments of sulfanilic acid solutions using a pre-pilot flow plant by response surface methodology," Journal of Hazardous Materials, vol. 221222, pp. 288-297, 2012.

[27] N. Ali, V. F. Neto, S. Mei et al., "Optimisation of the new timemodulated CVD process using the Taguchi method," Thin Solid Films, vol. 469-470, pp. 154-160, 2004.

[28] S. Maghsoodloo, G. Ozdemir, V. Jordan, and C. Huang, "Strengths and limitations of taguchi's contributions to quality, 
manufacturing, and process engineering," Journal of Manufacturing Systems, vol. 23, no. 2, pp. 73-126, 2004.

[29] G. Barman, A. Kumar, and P. Khare, "Removal of congo red by carbonized low-cost adsorbents: process parameter optimization using a Taguchi experimental design," Journal of Chemical and Engineering Data, vol. 56, no. 11, pp. 4102-4108, 2011.

[30] S. K. Gauri and S. Chakraborty, "Multi-response optimisation of WEDM process using principal component analysis," The International Journal of Advanced Manufacturing Technology, vol. 41, no. 7-8, pp. 741-748, 2009.

[31] P. J. Ross, Taguchi Techniques for Quality Engineering, McGrawHill, New York, NY, USA, 1998.

[32] M. Kaladhar, K. V. Subbaiah, C. Srinivasa Rao, and K. Narayana Rao, "Application of Taguchi approach and utility concept in solving the multi-objective problem when turning AISI 202 austenitic stainless steel," Journal of Engineering Science and Technology Review, vol. 4, no. 1, pp. 55-61, 2011.

[33] C. L. Hsueh, Y. H. Huang, C. C. Wang, and C. Y. Chen, "Degradation of azo dyes using low iron concentration of Fenton and Fenton-like system," Chemosphere, vol. 58, no. 10, pp. 1409-1414, 2005.

[34] S. Wang, "A Comparative study of Fenton and Fenton-like reaction kinetics in decolourisation of wastewater," Dyes and Pigments, vol. 76, no. 3, pp. 714-720, 2008.

[35] M. Neamtu, A. Yediler, I. Siminiceanu, and A. Kettrup, "Oxidation of commercial reactive azo dye aqueous solutions by the photo-Fenton and Fenton-like processes," Journal of Photochemistry and Photobiology A: Chemistry, vol. 161, no. 1, pp. 87-93, 2003.

[36] M. Y. Can, Y. Kaya, and O. F. Algur, "Response surface optimization of the removal of nickel from aqueous solution by cone biomass of Pinus sylvestris," Bioresource Technology, vol. 97, no. 14, pp. 1761-1765, 2006.

[37] B. K. Körbahti, "Response surface optimization of electrochemical treatment of textile dye wastewater," Journal of Hazardous Materials, vol. 145, no. 1-2, pp. 227-286, 2007.

[38] B. Bianco, I. de Michelis, and F. Vegliò, "Fenton treatment of complex industrial wastewater: optimization of process conditions by surface response method," Journal of Hazardous Materials, vol. 186, no. 2-3, pp. 1733-1738, 2011.

[39] C. T. Benatti, C. R. G. Tavares, and T. A. Guedes, "Optimization of Fenton's oxidation of chemical laboratory wastewaters using the response surface methodology," Journal of Environmental Management, vol. 80, no. 1, pp. 66-74, 2006.

[40] M. Ahmadi, F. Vahabzadeh, B. Bonakdarpour, E. Mofarrah, and M. Mehranian, "Application of the central composite design and response surface methodology to the advanced treatment of olive oil processing wastewater using Fenton's peroxidation," Journal of Hazardous Materials, vol. 123, no. 1-3, pp. 187-195, 2005.

[41] Y. W. Kang and K. Hwang, "Effects of reaction conditions on the oxidation efficiency in the Fenton process," Water Research, vol. 34, no. 10, pp. 2786-2790, 2000.

[42] S. Meriç, D. Kaptan, and T. Ölmez, "Color and COD removal from wastewater containing Reactive Black 5 using Fenton's oxidation process," Chemosphere, vol. 54, no. 3, pp. 435-441, 2004.

[43] M. E. Argun and M. Karatas, "Application of Fenton process for decolorization of reactive black 5 from synthetic wastewater: kinetics and thermodynamics," Environmental Progress \& Sustainable Energy, vol. 30, no. 4, pp. 540-548, 2011.
[44] A. Chowdhury, R. Chakraborty, D. Mitra, and D. Biswas, "Optimization of the production parameters of octyl ester biolubricant using Taguchi's design method and physico-chemical characterization of the product," Industrial Crops and Products, vol. 52, pp. 783-789, 2014.

[45] Ö. Gökkuş, Y. Ş. Yildiz, and B. Yavuz, "Optimization of chemical coagulation of real textile wastewater using Taguchi experimental design method," Desalination and Water Treatment, vol. 49, no. 1-3, pp. 263-271, 2012.

[46] O. Gökkuş and Y. Ş. Yıldız, "Investigation of the effect of process parameters on the coagulationflocculation treatment of textile wastewater using the taguchi experimental method," Fresenius Environmental Bulletin, vol. 23, no. 2, pp. 1-8, 2014.

[47] L. Hsieh, H. Kang, H. Shyu, and C. Chang, "Optimal degradation of dye wastewater by ultrasound/Fenton method in the presence of nanoscale iron," Water Science and Technology, vol. 60, no. 5, pp. 1295-1301, 2009. 

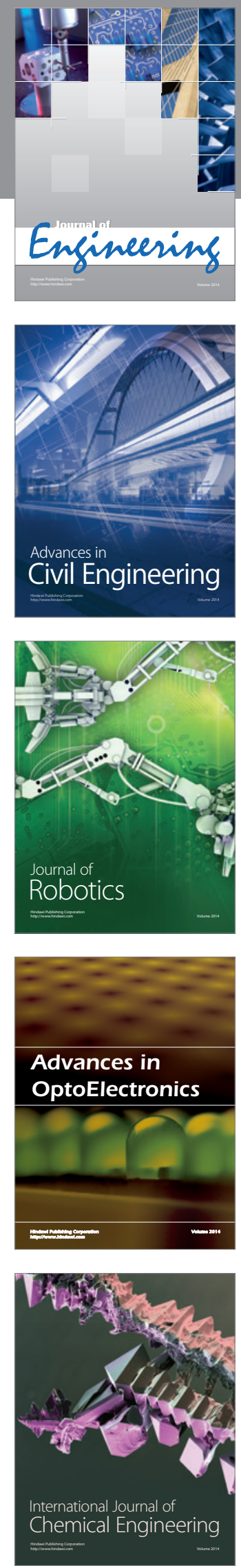

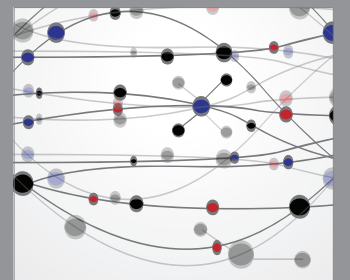

The Scientific World Journal
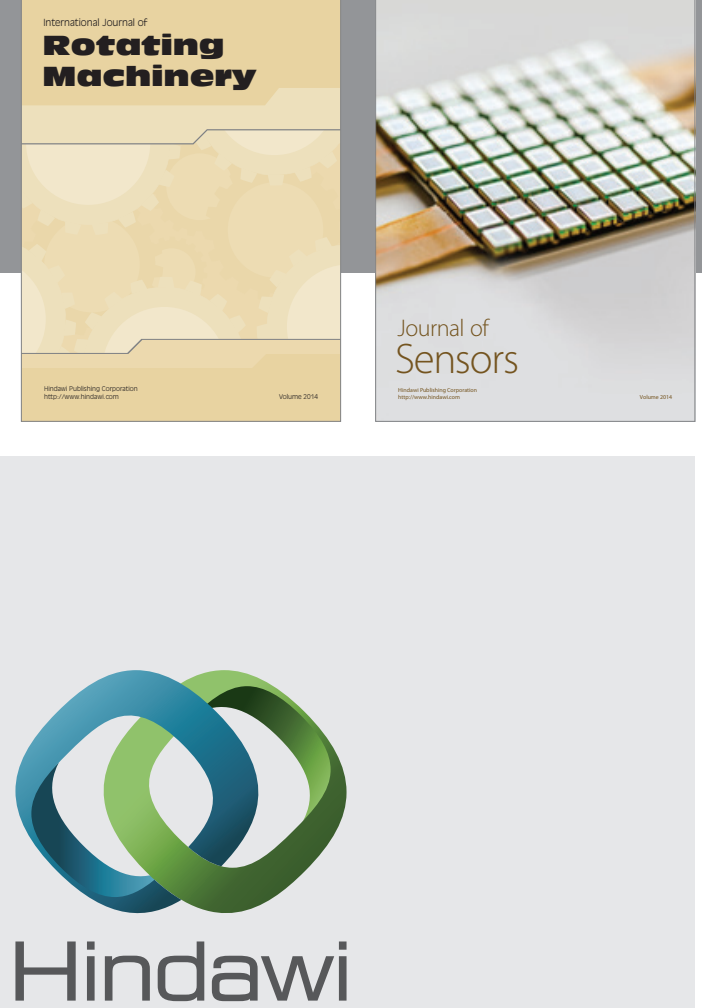

Submit your manuscripts at http://www.hindawi.com
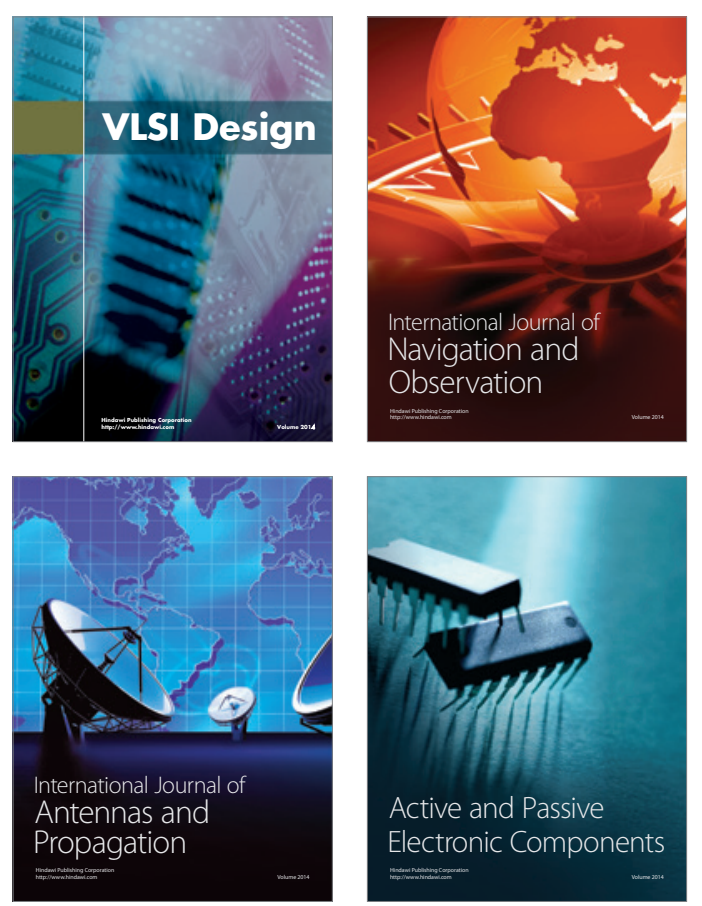
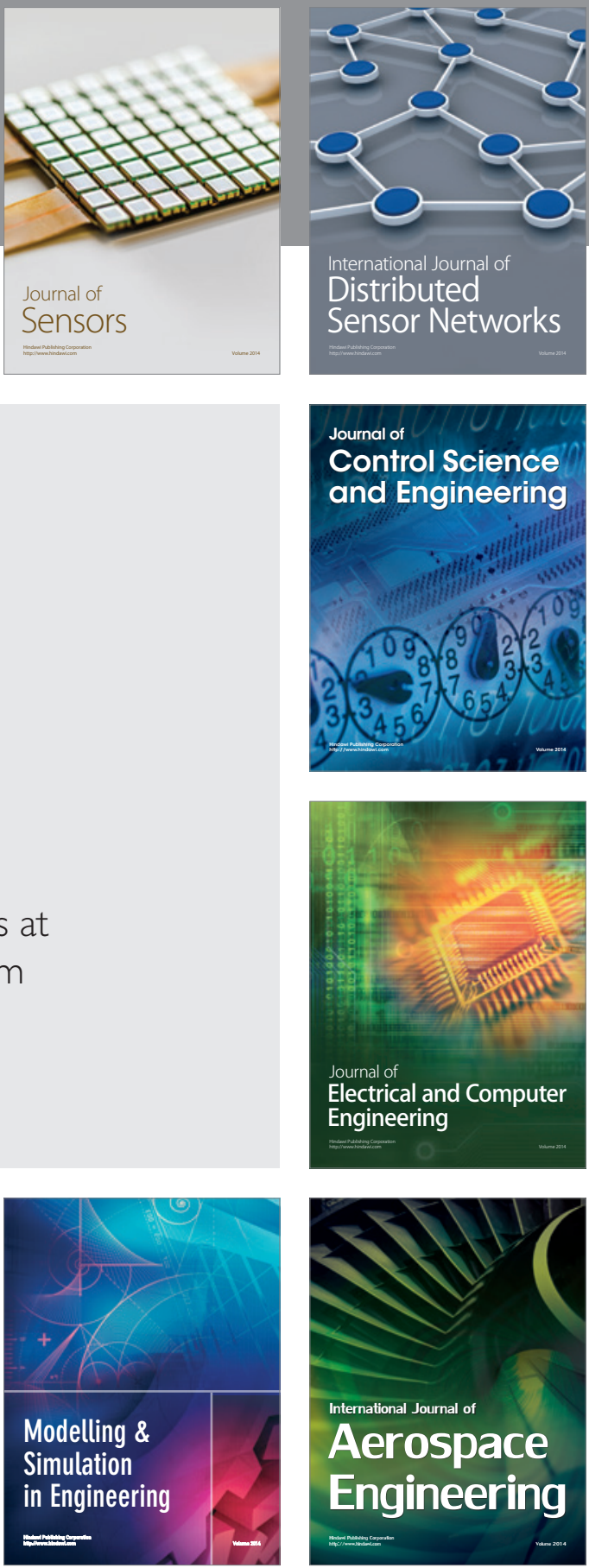

Journal of

Control Science

and Engineering
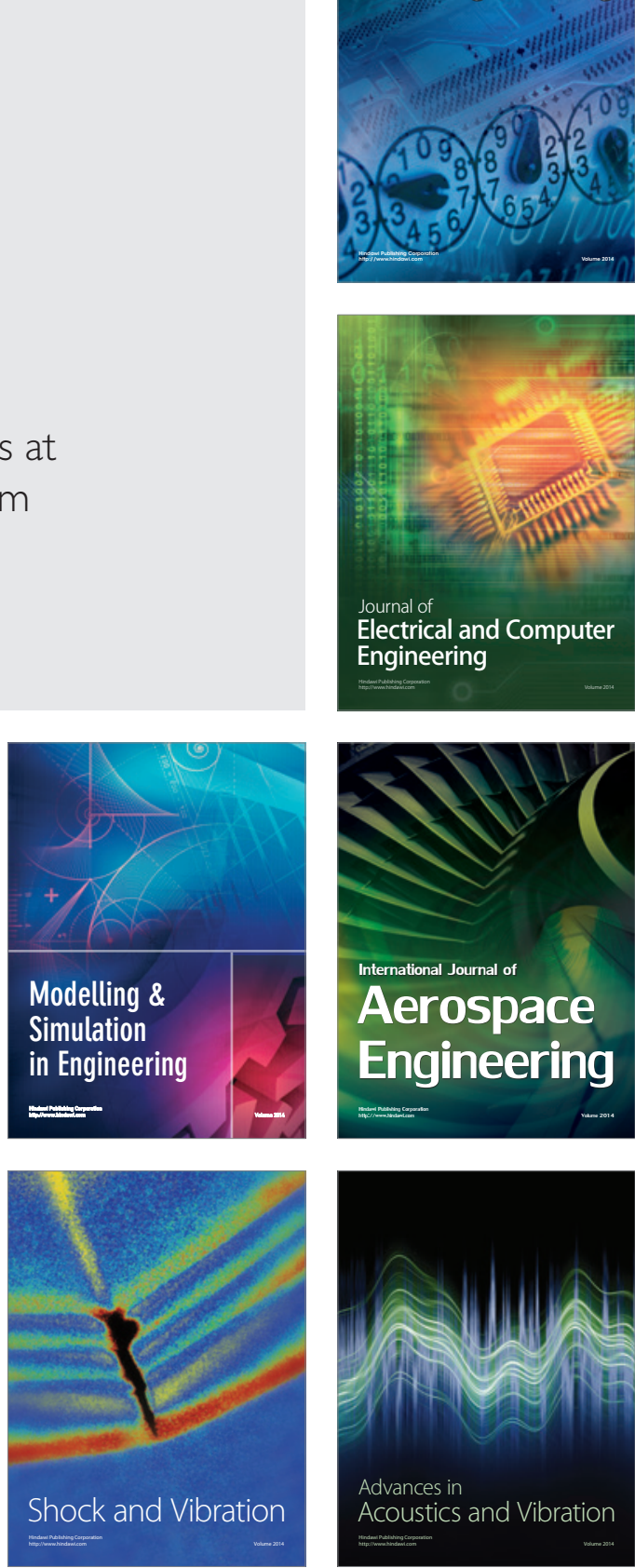